\title{
Cigarette smoking, hypertension and diabetes mellitus as risk factors for erectile dysfunction in upper Egypt
}

H. Zedan, ${ }^{1}$ A.A. Hareadei, ${ }^{1}$ A.A. Abd-Elsayed ${ }^{2}$ and E.M. Abdel-Maguid ${ }^{1}$

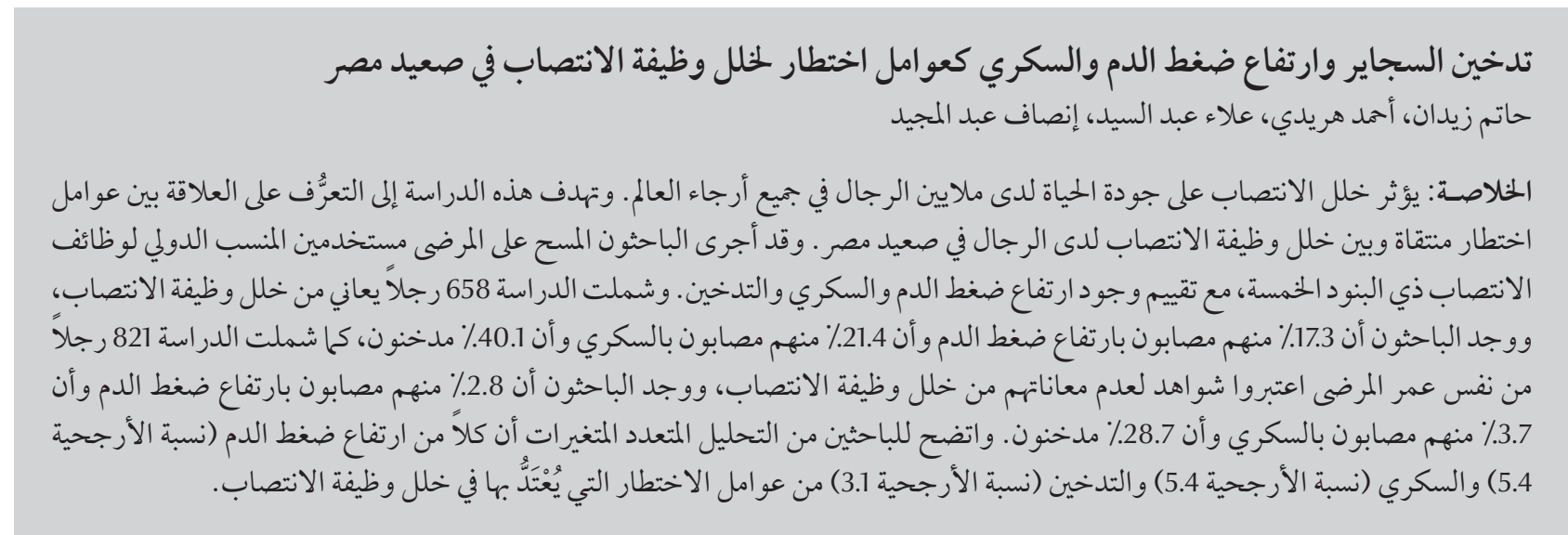

ABSTRACT Erectile dysfunction impairs the quality of life of millions of men worldwide. This study aimed to determine the relationship between selected clinical risk factors and erectile dysfunction in men residing in upper Egypt. Patients were surveyed with the 5-item International Index of Erectile Function (IIEF-5) and assessed for the presence of hypertension, diabetes and smoking. Of 658 men with erectile dysfunction, 17.3\% had hypertension, $21.4 \%$ had diabetes and $40.1 \%$ were smokers, whereas among 821 age-matched controls without erectile dysfunction, the corresponding figures were $2.8 \%, 3.7 \%$ and $28.7 \%$. Multivariate analysis showed that hypertension $(O R=5.4)$, diabetes mellitus $(O R=5.4)$ and smoking $(O R=3.1)$ were significant risk factors for erectile dysfunction.

\section{Tabagisme, hypertension et diabète comme facteurs de risque des troubles de l'érection en haute Égypte}

RÉSUMÉ Les troubles de l'érection perturbent la qualité de vie de millions d'hommes dans le monde. Cette étude visait à définir la relation entre certains facteurs de risque cliniques et les troubles de l'érection chez des hommes vivant en haute Égypte. L'étude était basée sur l'Index International de la Fonction Érectile contenant 5 items (5-item International Index of Erectile Function ou IIEF-5) et les patients étaient contrôlés au niveau de l'hypertension, du diabète et du tabagisme. Sur 658 hommes présentant des troubles de l'érection, $17,3 \%$ souffraient d'hypertension, 21,4 \% étaient diabétiques et 40,1 \% étaient des fumeurs, alors que parmi les 821 hommes du groupe témoin appariés selon l'âge ne souffrant pas de troubles de l'érection les chiffres correspondants étaient 2,8 \%, 3,7 \% et 28,7\%. L'analyse multivariée a montré que l'hypertension (risque relatif rapproché $=5,4$ ), le diabète (risque relatif rapproché $=5,4$ ) et le tabagisme (risque relatif rapproché $=3,1$ ) étaient des facteurs de risque importants pour les troubles de l'érection.

${ }^{7}$ Department of Dermatology and Andrology; ${ }^{2}$ Department of Public Health and Biostatistics, Faculty of Medicine, University of Assiut, Assiut, Egypt (Correspondence to A.A. Abd-Elsayed: alaaawny@hotmail.com).

Received: 29/10/07; accepted: 13/02/08 


\section{Introduction}

Erectile dysfunction (ED) is defined as the inability to achieve or maintain an erection sufficient to permit satisfactory sexual intercourse [1]. It is estimated that ED affects more than 150 million men worldwide, and impairs psychological well-being and personal relationships and hence quality of life [2]. The reported frequencies of ED vary substantially between different countries and populations, possibly due to differences in culture, diagnostic criteria, age distribution and concomitant medical conditions, as well as methodological differences [3-5]. The Massachusetts Male Aging Study indicated that the prevalence of ED was $52 \%$ in men aged $40-70$ years old and was strongly correlated with age $[5,6]$.

Common risk factors associated with ED include heart disease, hypertension, diabetes mellitus and cigarette smoking [7-23]. Prolonged elevated blood pressure has detrimental effects on the vascular system as a whole, including the penile blood supply $[13,14]$. It is now widely accepted that organic ED in a substantial majority of men occurs because of underlying vascular causes, especially atherosclerosis [15]. All antihypertensive agents, regardless of composition, have been implicated in causing $\mathrm{ED}[16,17]$. ED is also a common complication of diabetes mellitus [19-21], and ED is 2-4 times more prevalent among diabetic patients than nondiabetic individuals [18] with the reported prevalence ranging between $2 \%$ [7] and 75\% [19]. Several studies have demonstrated that cigarette smoking is associated with $\mathrm{ED}[8,10,11]$. Smokers are 1.5 times more likely to have ED than nonsmokers [14] and even 2 cigarettes per day may have a deleterious effect on erection [12].

In Egypt, a greater understanding of the frequency and risk factors for $\mathrm{ED}$ is required for further development of therapeutic strategies for ED. This study aimed to determine the relationship between cigarette smoking, hypertension and diabetes mellitus and ED in men residing in Upper Egypt.

\section{Methods}

\section{Study design}

This study was an analytical hospitalbased case-control study comparing cases of ED with a control group matched for age and residence (governorate and urban or rural). A pilot study was carried out on 20 cases to identify potential problems before starting the main study.

\section{Sample}

A total of 658 male patients aged over 20 years complaining of ED were included in this study. They were all patients who attended the andrology clinic of University of Assiut Hospital, Assiut, Egypt in the years 2003 to 2007. This hospital is the largest tertiary care centre in Upper Egypt, serving patients from Beni Suef in the north to Aswan in the south. In addition, 821 control men were included in this study who were normal patients visiting the hospital and not complaining of ED.

\section{Data collection}

After providing informed, witnessed verbal consent, all patients and controls were surveyed with 2 instruments: the International Index of Erectile Function, 5-item version (IIEF-5) [24] and a physician medical data collection form. The IIEF-5 is internationally recognized as a reliable, valid and sensitive evaluation instrument for assessing ED. It is a 5-point scale (score range 5-25) to rate a man's confidence in achieving and keeping an erection; the frequency that his erections are hard enough for penetration; his difficulty in maintaining an erection to completion of intercourse; and the frequency that attempted sexual intercourse is satisfactory. ED severity was defined as: none (IIEF-5 score
21-25); mild (score 18-21); mild to moderate (score 12-17); moderate (score 8-11); or severe (score 5-7).

The inclusion criteria for cases were: presented during the period of the study; resident in Upper Egypt; > 20 years old; diagnosed as having ED by history and IIEF-5 score $\leq 21$; free of major physical or psychological disabilities; and not receiving any psychiatric medication. The inclusion criteria for controls were: matched with cases for age and residence (governorate and urban or rural); diagnosed to be free from ED by history and IIEF-5 score $>21$; free of major physical or psychological disabilities; and not receiving any psychiatric medication.

The presence or absence of the following risk factors-smoking, hypertension and diabetes mellitus (type 1 or 2) - were determined in both patients and controls. A man was considered a smoker if he had smoked > 1 cigarette/ day for at least 1 year and a nonsmoker if he had never smoked more than 1 cigarette/day [22]. Heavy smoking was defined as tobacco consumption $>20$ cigarettes per day; moderate smoking as 10-20 cigarettes per day; and mild smoking as < 10 cigarettes per day. A man was defined as having hypertension if he had a systolic pressure $>160$ $\mathrm{mmHg}$ and/or a diastolic pressure $>$ $90 \mathrm{mmHg}$ and/or was currently taking drugs for hypertension [23]. A man was defined as having diabetes mellitus if he was currently taking drugs for this condition and/or he had fasting blood glucose $\geq 7.0 \mathrm{mmol} / \mathrm{L}$.

The physician's data collection form consisted of history-taking, clinical examination and investigation, e.g. level of smoking (mild, moderate or heavy) and the presence, nature and treatment of hypertension and diabetes, measurement of blood pressure and estimation of blood glucose level. 


\begin{tabular}{lccccc}
\hline \multicolumn{5}{l}{ Table 1 Age distribution of men with erectile dysfunction and control men } \\
$\begin{array}{lccccc}\text { Age group } \\
\text { (years) }\end{array}$ & \multicolumn{1}{c}{ Cases $(\boldsymbol{n}=\mathbf{6 5 8})$} & \multicolumn{1}{c}{ Controls $(\boldsymbol{n}=\mathbf{8 2 1})$} & $\boldsymbol{P}$-value \\
$20-<30$ & No. & $\%$ & No. & $\%$ & \\
$30-<40$ & 89 & 13.5 & 102 & 12.4 & 0.6 \\
$40-<50$ & 110 & 16.7 & 133 & 16.2 & 0.4 \\
$50-<60$ & 234 & 35.6 & 291 & 35.4 & 0.5 \\
$60-<70$ & 154 & 23.4 & 186 & 22.7 & 0.4 \\
$70-80$ & 58 & 8.8 & 83 & 10.1 & 0.2 \\
\hline
\end{tabular}

Table 2 Prevalence of hypertension, diabetes and smoking among men with erectile dysfunction and control men

\begin{tabular}{llcccc} 
Risk factor & \multicolumn{2}{c}{ Cases $(\boldsymbol{n}=\mathbf{6 5 8})$} & \multicolumn{2}{c}{ Controls $(\boldsymbol{n}=\mathbf{8 2 1})$} & $\boldsymbol{P}$-value \\
& No. & $\%$ & No. & $\%$ & \\
Hypertension & 114 & 17.3 & 23 & 2.8 & $<0.001$ \\
Diabetes mellitus & 141 & 21.4 & 30 & 3.7 & $<0.001$ \\
Smoking & 264 & 40.1 & 236 & 28.7 & $<0.001$ \\
\hline
\end{tabular}

\section{Ethical considerations}

Approval was obtained from our institution ethical committee. The aim of the study was explained to all participants. It was emphasized to them that they would not be harmed in the study and that refusal to participate would not affect their access to services and treatment in the hospital. Consent was obtained from all the participants and security and confidentiality of all the information obtained was observed. The IIEF-5 data were collected by personal interview with participants.

\section{Data analysis}

Data entry and analysis were done using SPSS, version 15. Data analysis included descriptive analysis with means and standard deviation (SD), $z$ test for comparing the percentage of participants in the different age classes between both groups, Yates corrected chi-squared test, Mann-Whitney test and logistic regression for analysis of risk factors.

\section{Results}

The study included 658 patients complaining of ED and 821 control men not complaining of ED. The duration of complaint varied from 1 month to 120 months. The mean age of the cases was 46.3(SD 23.5) years and of the controls was $44.5($ SD 20.2) years $(P=0.11)$. About $70 \%$ of the ED patients were over the age of 40 years (Table 1); 59.0\% were $40-60$ years old and $10.8 \%$ were 60-80 years old.

Of the 658 ED patients, 114 (17.3\%) suffered from hypertension,
141 (21.4\%) had diabetes mellitus and 264 (40.1\%) were smokers. Among the 821 control men, $23(2.8 \%)$ had hypertension, 30 (3.7\%) had diabetes mellitus and 236 (28.7\%) were smokers. The differences in the prevalence values for all 3 risk factors were statistically significant between the groups (all $P<0.001)$ (Table 2).

Among the studied ED patients, severe ED (IIEF-5 score 5-7) was recorded among $12.2 \%$ of hypertensive patients, $8.5 \%$ of diabetic patients and $7.2 \%$ of smokers (Table 3 ).

Multivariate analysis showed that the risk of having ED was more than 5 times higher in men with hypertension [odds ratio $(\mathrm{OR})=5.4,95 \%$ confidence interval $(\mathrm{CI}): 3.4-8.5, P<0.001]$ and diabetes mellitus $(\mathrm{OR}=5.4,95 \% \mathrm{CI}$ : 3.6-8.2, $P<0.001$ ), and around 3 times higher in smokers (OR $=3.1,95 \% \mathrm{CI}$ : 2.4-3.8, $P<0.001)($ Table 4$)$.

\section{Discussion}

A number of modifiable risk factors are associated with ED, including cigarette smoking, hypertension and diabetes mellitus [25].ED is a common problem among ageing men and the prevalence of ED increases with each decade of patient age [5]. In the present study, about $70 \%$ of patients were over age 40 years, indicating that age is strongly associated with ED. Feldman et al. analysed 1290 men in the Massachusetts Male Aging Study and concluded that "age was the variable most strongly associated with impotence" [5]. Of the patients in the current study $59.0 \%$ were in the age

Table 3 Prevalence of hypertension, diabetes and smoking by International Index of Erectile Function, 5-item version (IIEF-5) scores among men with erectile dysfunction (ED)

\begin{tabular}{llccccccc} 
Risk factor & \multicolumn{2}{c}{$\begin{array}{l}\text { Severe ED } \\
\text { (score 5-7) }\end{array}$} & \multicolumn{2}{c}{$\begin{array}{c}\text { Moderate ED } \\
\text { (score 8-11) }\end{array}$} & $\begin{array}{c}\text { Mild to moderate ED } \\
\text { (score 12-16) }\end{array}$ & \multicolumn{2}{c}{$\begin{array}{c}\text { Mild ED } \\
\text { (score 17-21) }\end{array}$} \\
& No. & $\%$ & No. & $\%$ & No. & $\%$ & No. & $\%$ \\
Hypertension & 14 & 12.2 & 41 & 36.0 & 49 & 43.0 & 10 & 8.8 \\
Diabetes mellitus & 12 & 8.5 & 59 & 41.8 & 60 & 42.6 & 10 & 7.1 \\
Smoking & 19 & 7.2 & 88 & 33.3 & 124 & 47.0 & 33 & 12.5 \\
\hline
\end{tabular}


group 40-60 years old compared with $10.8 \%$ in the group $60-80$ years old, which is not the same in more developed countries $[5,26]$. This reflects differences in social and cultural aspects in addition to different life expectancy rates in Upper Egypt compared to developed countries. It is known that men above the age of 60 years in Upper Egypt rarely seek medical advice for ED probably because they consider this problem as a normal consequence of ageing.

The association between smoking and $\mathrm{ED}$ has been reported in numerous studies that reported an increased incidence of ED among smokers $[5,9,27]$. Longitudinal data from the Massachusetts Male Aging Study showed that the incidence of ED was twice as high among smokers compared with nonsmokers over a 9-year period [28]. There is evidence of a beneficial effect of smoking cessation on ED, especially at younger ages [29]. In our study, smoking was reported by $40.1 \%$ of patients complaining of ED compared with $28.7 \%$ of controls. The probability of developing ED in smokers was 3 times higher than nonsmokers, which is similar to the results of Shiri et al. [30] and higher than that reported by Kupelian et al. [25].

Hypertension was detected in 114 patients who represented $17.3 \%$ of

\begin{tabular}{lcc}
\hline \multicolumn{3}{l}{ Table 4 Logistic regression analysis of risk factors for erectile dysfunction } \\
\hline Risk factor & OR $(95 \% \mathrm{CI})$ & $P$-value \\
Hypertension & $5.4(3.4-8.5)$ & $<0.001$ \\
Diabetes mellitus & $5.4(3.6-8.2)$ & $<0.001$ \\
Smoking & $3.1(2.4-3.8)$ & $<0.001$ \\
\hline
\end{tabular}

$O R=$ odds ratio $; C I=$ confidence interval.

the total number of cases compared with $2.8 \%$ of the controls. According to IIEF-5 scores, $12.2 \%$ of hypertensive patients had severe ED. A high prevalence of ED (43.2\%) was previously demonstrated in the Egyptian male population with hypertension [31]. According to Ponholzer et al. patients with hypertension developed ED 2 times more than nonhypertensive patients [24]. However, our study showed that the probability of developing ED in hypertensive patients was 5 times higher than in nonhypertensive patients. This difference could be attributed to differences in study design, age distribution, duration of hypertension and the antihypertensive drugs used by the study patients.

$\mathrm{ED}$ is a common complication of diabetes, with a prevalence ranging between $27 \%$ and $75 \%$ [19]. In our study, $21.4 \%$ of the total number of ED patients had diabetes mellitus compared with $3.7 \%$ of the controls. According to the IIEF- 5 scores, $8.5 \%$ of diabetic patients had severe ED. The probability of developing ED in men with diabetes was 5 times higher than in nondiabetic men. Previous studies demonstrated that ED was 2 to 4 times more prevalent among diabetic patients than nondiabetic individuals [18].

\section{Conclusion}

Our study estimated the prevalence of smoking, hypertension and diabetes mellitus among patients with ED in Upper Egypt compared with controls. We found that the probability of developing ED was very high in the presence of smoking, hypertension and diabetes mellitus. The results differ from those in other populations and countries possibly due to differences in culture, race, health services and methodology. Larger-scale studies on a national basis are needed to survey a greater number of populations for all risk factors associated with ED.

\section{References}

1. NIH Consensus Conference. Impotence. NIH Consensus Development Panel on Impotence. Journal of the American Medical Association, 1993, 270:83-90.

2. Lue TF. Erectile dysfunction. New England journal of medicine, 2000, 342:1802-13.

3. Papatsoris AG, Triantafyllidis A, Gekas A. Prevalence of erectile dysfunction in the European Union. Asian journal of andrology, 2003, 5:255.

4. Nicolosi A et al. Epidemiology of erectile dysfunction in four countries: cross national study of the prevalence and correlates of erectile dysfunction. Urology, 2003, 61:201-6.

5. Feldman HA et al. Impotence and its medical and psychosocial correlates: Results of the Massachusetts Male Aging Study. Journal of urology, 1994, 151:54-61.

6. Wessells $\mathrm{H}$ et al. Erectile dysfunction. Journal of urology, 2007, 177:1675-81.
7. Benet AE, Melman A. The epidemiology of erectile dysfunction. Urologic clinics of North America, 1995, 22:699-709.

8. Martin-Morales A et al. Prevalence and independent risk factors for erectile dysfunction in Spain: results of the Epidemiologia de la Disfuncion Erectil Masculina Study. Journal of urology, 2001, 166:569-75.

9. Bacon CG e et al. A prospective study of risk factors for erectile dysfunction. Journal of urology, 2006, 176:217-21.

10. Seyam RM et al. Prevalence of erectile dysfunction and its correlates in Egypt: a community based study. International journal of impotence research, 2003, 15:237-45.

11. McVary KT, Carrier S, Wessells H. Smoking and erectile dysfunction: evidence based analysis. Journal of urology, 2001, 166:1624-32.

12. Gilbert DG, Hagen RL, D'Agostino JA. The effects of cigarette smoking on human sexual potency. Addictive behaviours, 1986, 11:431-4. 
13. Ellis JL, Campos-Outcalt D. Cardiovascular disease risk factors in native Americans: a literature review. American journal of preventive medicine, 1994, 10:295-307.

14. Hypertension control. A report of WHO Expert Committee. World Health Organization technical report series, 1996 , 862:1-83.

15. Virag R, Bouilly P, Frydman D. Is impotence an arterial disorder? A study of arterial risk factors in 440 impotent men. Lancet, 1985, 1:181-4.

16. Goldstein I, Krane RJ. Drug induced sexual dysfunction. World journal of urology, 1983, 1:239-47.

17. Slag MF et al. Impotence in medical clinic outpatients. Journal of the American Medical Association, 1983, 249:1736-40.

18. Rosen RC et al. The multinational Men's Attitudes to Life Events and Sexuality (MALES) study. I. Prevalence of erectile dysfunction and related health concerns in the general population. Current medical research and opinion, 2004, 20:607-17.

19. Fedele $\mathrm{D}$ et al. Erectile dysfunction in type I and type II diabetics in Italy. International journal of epidemiology, 2000, 29:524-31.

20. Sasaki $\mathrm{H}$ et al. Prevalence and risk factors for erectile dysfunction in Japanese diabetics. Diabetes research and clinical practice, 2005, 70:81-9.

21. Romeo $\mathrm{JH}$ et al. Sexual function in men with diabetes type 2 association with glycemic control. Journal of urology, 2000, 163:788-91.

22. Austoni E. Smoking as a risk factor for erectile dysfunction: data from the andrology prevention weeks 2001-2002. A study of the Italian Society of Andrology. European urology, 2005, 48:810-8.
23. Fonseca V, Jawa A. Endothelial and erectile dysfunction, diabetes mellitus, and the metabolic syndrome: common pathways and treatments? American journal of cardiology, 2005, 96(Suppl.):13M-8M.

24. Rosen RC et al. Development and evaluation of an abridged, 5 -item version of the International Index of Erectile Function (IIEF-5) as a diagnostic tool for erectile dysfunction. International journal of impotence research, 1999, 11:319-26.

25. Saigal CS et al. Predictors and prevalence of erectile dysfunction in a racially diverse population. Archives of internal medicine, 2006, 166:207-12.

26. Ponholzer A et al. Prevalence and risk factors for erectile dysfunction in 2869 men using a validated questionnaire. European urology, 2005, 47:80-6.

27. Kupelian V, Link CL, McKinlay JB. Association between smoking, passive smoking, and erectile dysfunction: results from the Boston Area Community Health (BACH) Survey. European urology, 2007, 52:416-22.

28. Feldman HA et al. Erectile dysfunction and coronary risk factors: prospective results from the Massachusetts Male Aging Study. Preventive medicine, 2000, 30:328-38.

29. Polsky JY et al. Smoking and other lifestyle factors in relation to erectile dysfunction. BJU international, 2005, 96:1355-9.

30. Shiri R et al. Smoking causes erectile dysfunction through vascular disease. Urology, 2006, 68:1318-22.

31. Mittawae B et al. Incidence of erectile dysfunction in 800 hypertensive patients: a multicenter Egyptian national study. Urology, 2006, 67:575-8.

\section{Global Adult Tobacco Survey in Egypt}

The Ministry of Health (MoH) of Egypt, the Central Agency for Public Mobilization and Statistics (CAPMAS) and the World Health Organization (WHO) released key findings from the Global Adult Tobacco Survey in Egypt on Thursday, 28 January 2010. The Global Adult Tobacco Survey, which was conducted in 2009, is a standardized global survey for systematically monitoring adult tobacco use (smoked and smokeless) and tracking key tobacco control indicators. The MoH, CAPMAS and the WHO Representative's Office in Egypt are the three national partners who collaborated in this survey.

The survey was conducted in all of Egypt's governorates, covering both males and females, aged 15 years and older, in a total sample size of 23760 . One of the key findings revealed by the survey is that $38 \%$ of Egyptian males use some form of tobacco product. Of this percentage, nearly $32 \%$ smoke cigarettes, about $6 \%$ smoke shisha and almost $5 \%$ chew tobacco.

Tobacco use constitutes a serious health burden on Egyptian society, and also on the health system, due to the cost of providing health care for smokers.

Further information about the Tobacco Free Initiative can be found at: http://www.emro.who.int/tfi/tfi.asp 